\title{
Construindo pontes entre cidadão e setor público: estudo de caso na ouvidoria da CELESC
}

\begin{abstract}
A ouvidoria pública tem como principal atribuição ser uma instituição que estabeleça ligação entre a administração pública e os cidadãos. Dessa forma, pode-se afirmar que ela busca promover a participação cidadã, o exercício da cidadania e o controle social. A ouvidoria possibilita a administração pública receber informações originárias da sociedade, e, a partir delas, torna-se possível a melhoria e aprimoramento contínuo dos serviços públicos prestados. Apreciada a relevância da ouvidoria pública, o objetivo deste artigo é ampliar os estudos sobre ouvidorias públicas a partir de uma realidade específica, no caso, a Ouvidoria da Centrais Elétricas de Santa Catarina S. A. - Celesc. Com atuação desde 1996, a ouvidoria da CELESC é a mais antiga do Estado de SC, por isso, a escolha deste órgão como objeto de análise. Para tanto, empreendeuse um estudo exploratório, de abordagem qualitativa, mediante a realização de entrevistas com o Ouvidor e a equipe da ouvidoria. Buscou-se identificar a estrutura, o funcionamento, os aspectos gerenciais e as possíveis contribuições na participação cidadã e controle social. Entre os principais resultados, destaca-se que a ouvidoria da Celesc, na percepção dos entrevistados, possui papel solidificado na organização e contribui para a melhoria dos serviços e participação cidadã. Ainda, o estudo traz algumas reflexões sobre aspectos relevantes ao funcionamento de uma ouvidoria e propõe sugestões de novas pesquisas sobre o tema.
\end{abstract}

Palavras-chave: Ouvidoria Pública; Participação; Controle Social.

\section{Building bridges between citizens and public administration: a case study at CELESC ombuds office}

\begin{abstract}
As main assignment, Public Service Ombuds Office should be an institution that connects Public Administration and citizens. By doing so, it seeks to promote both citizen participation and social control. This kind of ombuds office enables Public Administration receive, from citizens, different sorts of information. From them, it is possible the ongoing improvement in public services. Once presented its importance, this study aims to enlarge the understanding about Public Service Ombuds Office by analysing a specific context: the ombuds office of Centrais Elétricas de Santa Catarina S. A. - Celesc. Celesc Ombuds Office operates since 1996, which characterizes the oldest Public Service Ombuds Office in Santa Catarina state. Therefore, it was chosen as research object. The present study has an exploratory and qualitative approach. Data was collected by applying in depth interview with the Celesc Ombudsman and interviews with his team. The research sought to identity structure, functioning, managerial aspects and contributions to citizens participation in Celesc Ombuds Office. As main results, is pointed that the ombuds office has a solid role at Celesc and contributes to service improvement and citizens participation. Besides, the study brings some questions about relevant aspects concerning public ombuds office functioning and suggests other research possibilities on this area.
\end{abstract}

Keywords: Public Ombudsman; Participation; Social Control.

Topic: Gestão Pública

Reviewed anonymously in the process of blind peer.

Fernanda Chichorro Stahelin

Universidade do Estado de Santa Catarina, Brasil

http://lattes.cnpq.br/4513127402420988

fernanda chichorro@hotmail.com

Aline Regina Santos

Universidade Federal de Santa Catarina, Brasil

http://lattes.cnpq.br/9210124458700096

aline.santos@udesc.br

Jane lara Pereira da Costa

Universidade Federal de Santa Catarina

http://lattes.cnpq.br/5450672714788848

jane.costa@udesc.br

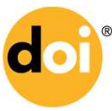

DOI: 10.6008/SPC2179-684X.2016.001.0019
Received: 08/10/2015

Approved: 17/03/2016
Referencing this:

STAHELIN, F. C.; SANTOS, A. R.; COSTA, J. I. P.. Construindo pontes entre cidadão e setor público: estudo de caso na ouvidoria da CELESC. Revista Brasileira de Administração Científica, v.7, n.1, p.277-296, 2016. DOI: http://doi.org/10.6008/SPC2179-684X.2016.001.0019 


\section{INTRODUÇÃO}

A ouvidoria pública é um instrumento que possibilita a aproximação entre o cidadão e a administração pública, ela permite o diálogo entre a população e o poder público. "A Ouvidoria, como canal direto de comunicação entre o cidadão e as organizações, deve atuar como o mediador natural, possibilitando um diálogo pacífico em busca de uma solução satisfatória para o conflito. " (CGU-OGU, 2015).

Além de possibilitar a comunicação, é função de uma ouvidoria pública apontar possíveis melhorias nos serviços prestados, a partir de avaliações das políticas e serviços. Segundo a Controladoria Geral da União (2015) "Isso é possível a partir das informações obtidas com a análise das manifestações, com a escuta dos cidadãos, mediante a realização de pesquisas de satisfação e do levantamento de expectativas e necessidades".

Ainda é razoável apontar como função de uma ouvidoria pública a promoção da participação cidadã. "A ouvidoria funciona como uma ponte entre as instituições e a sociedade visando a prestação de um serviço público de qualidade e que atenda ao cidadão" (CGU-OGU, 2015).

Para atender as suas funcionalidades é inerente ao sucesso de uma ouvidoria sua independência e autonomia. Com objetivo de preservá-las, é indispensável que na estrutura hierárquica da organização a ouvidoria esteja vinculada diretamente a instância máxima, viabilizando o não comprometimento de suas ações. Sem autonomia a ouvidoria não consegue contribuir para o fortalecimento da democracia.

O ouvidor merece destaque na atuação da ouvidoria, uma vez que ele é o porta voz do cidadão dentro do âmbito administrativo. A função do ouvidor é baseada nos princípios constituições de legitimidade, imparcialidade, publicidade, moralidade e eficiência. (CGU-OGU, 2012). Cabe ao ouvidor, transportar as manifestações recebidas aos setores responsáveis dentro da organização e, posteriormente, responder ao cidadão manifestante.

As manifestações podem ser classificadas como: reclamação, denúncia, elogio, solicitação ou sugestões de melhoria. De acordo com Controladoria Geral da União - Ouvidoria Geral da União (2015) manifestar é "o ato de expor, apresentar, declarar, demandar, enfim, é ato que expressa o exercício de três direitos fundamentais: o de livre manifestação do pensamento (art. 5ํ, IV), o de petição (art. 5ㅇ, XXXIV) e o de participação na administração pública (art. 37, §3ำ)". Os direitos fundamentais citados estão presentes na Constituição Federal de 1988, conhecida como constituição cidadã, a qual trouxe inovações ao Brasil relacionadas aos aspectos que garantem o acesso à cidadania. Cabe destacar o artigo 37, já que nele são indicadas formas de controle social e de fiscalização:

§ 3o A lei disciplinará as formas de participação do usuário na administração pública direta e indireta, regulando especialmente: (I - as reclamações relativas à prestação dos serviços públicos em geral, asseguradas a manutenção de serviços de atendimento ao usuário e a avaliação periódica, externa e interna, da qualidade dos serviços; (Incluído pela Emenda Constitucional no 19, de 1998)

II - o acesso dos usuários a registros administrativos e a informações sobre atos de governo, observado o disposto no art. 5o, X e XXXIII; (Incluído pela Emenda Constitucional no 19, de 1998) 
III - a disciplina da representação contra o exercício negligente ou abusivo de cargo, emprego ou função na administração pública. (Incluído pela Emenda Constitucional no 19, de 1998). (BRASIL, 1988)

Segundo a Ouvidoria Geral da União (OGU, 2012, p.18), cada vez mais a Ouvidoria exerce papel de fundamental importância devido à complexidade da Administração pública brasileira e, principalmente, pelo fato de funcionar como controle social da qualidade do serviço público, auxiliando na busca de soluções para os problemas.

A ouvidoria pública vem tornando-se gestão pública, um instrumento inovador, existindo a finalidade de que a cidadania seja plena e, assim, possa contribuir com o processo de democratização (CARDOSO, 2010).

Apesar de relevantes, os estudos sobre ouvidorias públicas são muito incipientes no Brasil. De acordo com trabalho "A Produção Acadêmica sobre Ouvidoria Pública: um Estudo em Eventos e Periódicos no Período de 2002 a 2013" apresentado no XXXIX Encontro da ANPAD - EnANPAD 2015 "o tema ainda se encontra em consolidação, pelo menos no âmbito das universidades, faculdades, centros universitários e grupos de pesquisa." O mesmo trabalho indica "um cenário com baixa produção acadêmica, quando abordada a temática da ouvidoria pública".

Considerando a importância do tema, as possíveis contribuições para o exercício da cidadania e a baixa produção acadêmica, o presente estudo teve como objetivo compreender a atuação da ouvidoria pública, a partir de um caso específico, a ouvidoria da Centrais Elétricas de Santa Catarina S. A. - Celesc. Foi escolhida a Ouvidoria Celesc, pelos seguintes motivos: a) é considerada a ouvidoria mais antiga do Estado de Santa Catarina, com origem no ano de 1996; b) a Celesc presta serviço de interesse coletivo, sendo elencado como essencial pela Lei Federal ํo 7.783, de 28 de junho de 1989 “Art. 10: São considerados serviços ou atividades essenciais: I-tratamento e abastecimento de água, produção e distribuição de energia elétrica, gás e combustíveis". Trata-se, portanto, de um estudo exploratório, qualitativo, que buscou trazer elementos para iniciar a construção de uma compreensão mais ampla sobre o universo das ouvidorias públicas do Brasil.

\section{REVISÃO TEÓRICA}

\section{Ouvidoria Pública}

A ouvidoria é atividade existente desde o século XIX. A literatura demonstrada por Amaral Filho (1993) indica como surgimento das ouvidorias a instituição da figura do "Ombudsman", promulgada na Constituição da Suécia no ano de 1809. O ouvidor teria o papel de representante do rei com o objetivo de:

Controlar a observação das leis pelos tribunais e funcionários e processar junto aos tribunais competentes, conforme as leis, aqueles que no exercício de suas funções tenham, por parcialidade, favor ou qualquer outro motivo, cometido ilegalidades ou negligenciado o cumprimento adequado de seus deveres de ofícios. (AMARAL FILHO, 1993)

Com o passar dos anos a figura do Ouvidor tem aumentado sua atuação em diversos países, fazendose presente em organizações da Administração Pública e Privada. O principal objetivo da ouvidoria pública é estabelecer um elo de comunicação entre a administração e o cidadão. Segundo a Cartilha de Implantação de Ouvidorias, desenvolvida pela Controladoria Geral da União e Ouvidoria Geral da União (2012) "a 
ouvidoria deve funcionar como um agente promotor de mudanças, favorecendo uma gestão flexível e voltada para a satisfação das necessidades do cidadão, garantindo uma prestação de serviços públicos de qualidade, de forma a garantir direitos".

É importante ressaltar a figura do ouvidor, já que as atividades pertinentes as ouvidorias são exercidas por ele, sendo o porta voz do cidadão na organização. É fundamental compreender que a ouvidoria é a ferramenta capaz de aproximar a gestão pública do cidadão, funcionando como um canal de comunicação de extrema importância na relação da sociedade com o Estado, e o ouvidor é quem coloca isto em prática.

Com a modernização da sociedade as organizações sofreram transformações que influenciaram diretamente no papel do ouvidor. A partir disso, o ouvidor deixou de ser aquela figura controladora e fiscalizadora conceituada no modelo clássico sueco, e passou a ser moldada de acordo com as necessidades da sociedade na qual está inserido. Existem características indispensáveis no perfil do ouvidor, são elas: ética, independência, autonomia, responsabilidade, transparência, honestidade, paciência, sigilo, imparcialidade, justiça. Atualmente, está surgindo a necessidade de um ouvidor-gestor, ou seja, além das características citadas o ouvidor precisa gerenciar a ouvidoria de forma a torná-la eficiente e eficaz na sua finalidade.

As informações recebidas pela ouvidoria não têm como objetivo fazer ou desfazer atos de gestão praticados no âmbito da organização. Deve funcionar como instrumento de coleta de informações das necessidades da população, identificando os pontos a serem aprimorados e contribuindo para o aperfeiçoamento dos serviços prestados pela administração pública. De acordo com a Cartilha de Implantação de Ouvidorias $(2012,13)$ "a ouvidoria tem por propósito buscar soluções para as demandas dos cidadãos; oferecer informações gerenciais e sugestões ao órgão em que atua, visando o aprimoramento da prestação do serviço, além de contribuir para a formulação de políticas públicas".

Existe uma relação próxima entre ouvidoria e o termo accountability. Santos (2011) esclarece que:

accountability significa a obrigação do Administrador Público prestar contas de forma clara e objetiva, especialmente demonstrando os resultados atingidos em função da sua posição institucional e do poder que detém; responsabilizando-se, assim, perante a sociedade por suas ações ou omissões em relação às políticas públicas executadas.

A ouvidoria pode ser considerada uma ferramenta de accountability na concepção do Novo Serviço Público. Nessa percepção ela está baseada em uma dimensão ampla, caracterizada pela capacidade do agente público de compreender e de responder às necessidades e expectativas dos cidadãos. Vale destacar que somente a existência da ouvidoria não garante o efetivo controle social, isso dependerá do desenho institucional que assegure o modelo democrático de participação.

Por meio da troca de informações entre a sociedade e o estado é possível estabelecer uma relação de confiança, trazendo benefícios para ambas as partes. É pressuposto entre o cidadão e o agente que desempenha a função de ouvidor uma relação baseada em confiança e boa-fé. É possível identificar isso pela legislação paulista que estabelece os seguintes deveres para o ouvidor (Decreto Estadual no 44.704/99, art.4ㅇ):

I - dar sempre ao cidadão uma resposta à questão apresentada, no menor prazo possível, com clareza e objetividade; II - atender com cortesia e respeito, afastando-se de qualquer discriminação ou pré-julgamento; III - agir com integridade, transparência, imparcialidade 
e justiça; IV - zelar pelos princípios da legalidade, impessoalidade, moralidade, publicidade e eficiência da administração pública; $V$ - resguardar o sigilo das informações.

É necessário que exista comunicação, segundo Bordenave (1992), é preciso que o cidadão saiba o que pode ser reclamado e com quem. Para isso, os canais devem ser visíveis, de amplo e fácil acesso, além de possuírem definição de seus limites. Bordenave (1992) explica que:

Em primeiro lugar, de informação: não há participação popular sem informação qualitativamente pertinente e quantitativamente abundante sobre os problemas, os planos e os recursos públicos. Em segundo lugar, canais de consulta. Em terceiro lugar, canais de reivindicação e de protesto.

O sucesso da ouvidoria não depende somente da estrutura organizacional, mas também do envolvimento e iniciativa de uma sociedade que deseje receber um serviço público de qualidade e seja capaz de exigi-lo.

\section{A Ouvidoria Pública no Brasil}

A origem da Ouvidoria no Brasil remete ao período colonial. Com a criação do Governo-Geral do Brasil surgiu o Ouvidor-Geral, o qual tinha competência para julgar e punir os infratores. A figura do ouvidor brasileiro neste período é totalmente distinta da instituição sueca do "Ombudsman". Segundo Braz (1992), enquanto o Ouvidor do modelo sueco representa os cidadãos, o Ouvidor-Geral no Brasil representa os interesses do titular do poder.

Por meio do processo de redemocratização e reforma administrativa brasileira, a instituição da Ouvidoria assemelha-se ao modelo clássico da Suécia, porém existe uma diferença significativa entre elas. $O$ modelo clássico do ouvidor está ligado ao poder legislativo e no Brasil a grande maioria das ouvidorias está relacionada ao poder executivo.

A consolidação das ouvidorias inicia-se a partir de 1986, ano de criação da primeira ouvidoria na esfera de governo, na cidade de Curitiba, no Paraná. A partir disso, o processo de criação de ouvidorias passou a ser difundido no Brasil nas áreas pública e privada, com o objetivo de identificar as necessidades, críticas e sugestões dos clientes ou cidadãos.

Um breve histórico relacionado à Ouvidoria no Brasil torna-se pertinente. Começando pelo ano 1986, mesmo ano de criação da primeira ouvidoria, é criada a Comissão de Defesa dos Direitos do Cidadão vinculada à Presidência da República contra abusos, erros e omissões na Administração Pública Federal. Em 1990 ocorre a criação do Código de Defesa do Consumidor, dois anos depois, é criada a Ouvidoria Geral da República na estrutura regimental básica do Ministério da Justiça, por meio da Lei Federal no 8.490, de 19 de novembro de 1992. No ano de 2005 é fundada a Associação Brasileira de Ouvidorias - ABO. Os Decretos nos 1.796/1996 e 2.802/1998 delegam ao Gabinete do Ministro da Justiça as competências para desenvolver as atividades de Ouvidoria-Geral da República. No ano seguinte, 1999, é promulgada no Estado de São Paulo, a lei de proteção ao usuário do serviço público, a qual determinada a criação de ouvidorias em todos os órgãos estaduais. Em 2000 o Secretário Nacional de Direitos Humanos do Ministério da Justiça recebe funções de Ouvidor-Geral da República. Já em 2001 é criada a Corregedoria-Geral da União, que integra a Presidência 
da República e em 2002 as competências de ouvidoria-geral do Ministério da Justiça é transferida para a Corregedoria, com exceção das relativas à de direitos humanos que permaneceram no Ministério da Justiça. No dia 28 de maio de 2003 a Lei Federal no 10.683, transforma a Corregedoria-Geral da União em Controladoria Geral da União. E por fim, em 2004 a Lei Federal no 10.689/2004 ajusta a denominação de Ouvidoria-Geral da República para Ouvidoria-Geral da União.

Com base nos dados da Ouvidoria Geral da União (BRASIL, 2009b), o crescimento das ouvidorias brasileiras é significante no período de 2002 a 2008, período esse, que o número de unidades passou de apenas 40 para 149, como se observa na tabela 1. Segundo Controladoria Geral da União (2013) o número de ouvidoria do Poder Executivo Federal, no ano de 2013, é de 271, o que demonstra um crescimento de aproximadamente $270 \%$ no número de ouvidorias no intervalo de seis anos.

Tabela 1: Evolução no quantitativo de Ouvidorias existentes no Poder Executivo Federal.

\begin{tabular}{|c|c|c|c|c|c|c|c|}
\hline \multirow{2}{*}{ Unidades de Ouvidoria } & \multicolumn{9}{|c|}{ Ano } & $\mathbf{2 0 0 6}$ & $\mathbf{2 0 0 7}$ & $\mathbf{2 0 0 8}$ \\
\cline { 2 - 10 } & $\mathbf{2 0 0 2}$ & $\mathbf{2 0 0 3}$ & $\mathbf{2 0 0 4}$ & $\mathbf{2 0 0 5}$ & $\mathbf{2 0 0 6}$ & 138 \\
\hline Quantitativo & 40 & 85 & 114 & 124 & 133 & 138 & 149 \\
\hline
\end{tabular}

Fonte: Brasil (2009b)

É possível identificar, especialmente após a Constituição Federal do Brasil de 5 de outubro de 1988, a crescente valorização de uma gestão pública que reconhece a importância da participação popular. “Um governo democrático aberto à participação é aquele que informa corretamente, ouve cuidadosamente e consulta ativamente a população" (BORDENAVE, 1992).

Para Lyra (2004), existem quatro experiências nacionais de destaque acerca da inclusão e participação popular pós Constituição Federal de 1988: I) as consultas populares previstas na CF/88, quais sejam, referendo, plebiscito e iniciativa popular de lei; II) o orçamento participativo; III) os Conselhos Gestores e de Fiscalização de Políticas Públicas; e IV) as ouvidorias, que não foram expressamente previstas na Constituição, mas correspondem a mais bem acabada expressão do princípio da participação do usuário na administração pública, introduzido expressamente no texto constitucional pela reforma administrativa (Emenda Constitucional no 19/1998).

A partir da configuração teórica e pressupostos legais sobre ouvidoria pública, fica nítida sua relevância para a administração pública, uma vez que envolve questão norteadora da Constituição Federal de 1988, a participação social, a qual por sua vez produz consequências amplas para a democracia.

\section{METODOLOGIA}

Neste estudo, utiliza-se a abordagem exploratória e qualitativa. A pesquisa exploratória, segundo Gil (2008) tem como objetivo "proporcionar visão geral, de tipo aproximado, acerca de determinado fato" e como finalidade "desenvolver, esclarecer e modificar conceitos e ideias". A pesquisa qualitativa de acordo com Creswell (2007), "emprega diferentes alegações do conhecimento, estratégia de investigação e métodos de coleta e análise de dados". O autor ainda afirma que "procedimentos qualitativos têm passos únicos de análise de dados e usam estratégias diversas de investigação" (2007). 
O objeto de estudo foi a Centrais Elétricas de Santa Catarina S.A. - Celesc, a organização foi criada a partir do Decreto Estadual no 22, de 09 de dezembro de 1955 com o objetivo de planejar, construir e explorar o sistema de produção, transmissão e distribuição de energia elétrica do Estado de Santa Catarina. A partir de outubro de 2006 foi estruturada como Holding, com duas subsidiárias integrais, a Celesc Geração S.A. e a Celesc Distribuição S.A. Juntas, as três empresas possuem mais de três mil profissionais.

A CELESC faz parte da administração pública indireta, classificada como Sociedade de Economia Mista, ou seja, é composta por capital público e privado e deve ter majoritariamente o capital público, pois a maioria das ações precisa estar sob controle do Estado. Por ser caracterizada dessa forma, a Celesc têm a finalidade de prestar serviços de interesse coletivo, e além disso, sua ouvidoria é a mais antiga do Estado de Santa Catarina, desta forma é justificada sua escolha para ser unidade de análise do estudo.

Entrevista em profundidade e entrevista mediante uso de questionário semiestruturado foram as técnicas utilizadas para o levantamento de dados, tendo como instrumentos roteiro e questionário, respectivamente. A entrevista foi realizada com o ouvidor geral da Celesc, Sr. Romualdo Luiz Dambroz, e o questionário com os seis membros da equipe da ouvidoria, ambos no período entre março e abril de 2015. A entrevista durou em média duas horas, obteve autorização para ser gravada, fato que resultou sua transcrição em inteiro teor. Já os questionários foram concluídos em menor tempo, aproximadamente 30 minutos cada, e suas repostas analisadas individualmente.

O instrumento de coleta de dados foi desenvolvido com base nas funcionalidades de uma ouvidoria pública presentes na Cartilha de Implantação de Ouvidoria (CGU-OGU, 2012). As funcionalidades foram categorizadas em três dimensões, a saber: dimensão funcional, gerencial e cidadã. A categorização deu-se a partir da análise "das perspectivas de atuação de uma unidade de ouvidoria pública" (CGU-OGU, 2012), como indicado no quadro 2.

Tabela 2: Categorização da perspectiva de atuação em dimensões.

\begin{tabular}{|l|c|}
\hline \multicolumn{1}{|c|}{ Perspectiva de atuação } & Dimensões \\
\hline Facilitar ao usuário dos serviços prestados o acesso às informações & Funcional \\
\hline Viabilizar o bom relacionamento do usuário do serviço com a instituição & Funcional \\
\hline $\begin{array}{l}\text { Sensibilizar os dirigentes das unidades da instituição no sentido de aperfeiçoar processos em prol da } \\
\text { boa prestação do serviço público }\end{array}$ & Gerencial \\
\hline Contribuir para o aprimoramento dos serviços prestados e das políticas públicas da instituição & Gerencial \\
\hline Contribuir para o aperfeiçoamento das normas e procedimentos da instituição & Gerencial \\
\hline Contribuir para a melhoria do desempenho e da imagem da instituição & Gerencial \\
\hline Proporcionar maior transparência das ações da instituição & Cidadã \\
\hline Incentivar a participação popular na modernização dos processos e procedimentos da instituição & Cidadã \\
\hline Incentivar a valorização do elemento humano na instituição & Cidadã \\
\hline
\end{tabular}

\section{RESULTADOS}

Em seguida, serão apresentados os resultados, que englobam a estrutura da Ouvidoria, o papel e perfil do ouvidor, o perfil da equipe, de que forma as atividades cotidianas impactam na gestão pública e qual a realidade das dimensões funcional, gerencial e cidadã na organização.

\section{Estrutura da Ouvidoria}


A ouvidoria da Celesc funciona há dezenove anos, sendo que o termo "Ombudsman" foi citado pela primeira vez na empresa no Acordo Coletivo de Trabalho - ACT 1995/1996. Com a justificativa de visar o interesse da sociedade e em razão de caráter público, a ouvidoria foi instituída no ano 1996. Ela está presente na área de distribuição de energia, pois é nessa área que existe o contato direto com o cidadão na prestação de serviço.

Foi questionado ao ouvidor qual o motivo da empresa possuir ouvidoria própria já que do Estado de Santa Catarina possui uma ouvidoria geral. O mesmo explicitou que ocorreu por dois motivos, o primeiro é que a ouvidoria estadual surgiu posteriormente à ouvidoria da Celesc e o segundo motivo é a regulamentação da ANEEL. O ouvidor afirmou que existe uma relação com a Ouvidoria Geral do Estado de Santa Catarina. Nós temos um vínculo com ela e quando tem alguma demanda do setor elétrico que entra na ouvidoria do estado, eles mandam através de link pra gente e a gente trabalha internamente e depois devolve a resposta.

Conforme o Artigo $2^{\circ}$ da Lei Federal no 9.427, de 26 de dezembro de 1996 a Agência Nacional de Energia Elétrica - ANEEL tem por finalidade regular e fiscalizar a produção, transmissão, distribuição e comercialização de energia elétrica, em conformidade com as políticas e diretrizes do governo federal.

De acordo com suas atribuições e tendo em vista que a Celesc Distribuição S.A. é regulada pela ANEEL, no ano de 2011 o referido órgão regulador, por meio da Resolução Normativa $n^{\circ}$ 470, de 13 de dezembro de 2011, estabeleceu as disposições relativas às Ouvidorias das concessionárias de serviço público de distribuição de energia elétrica. A Resolução Normativa torna obrigatória a implementação da ouvidoria em todas as agências distribuidoras, que são aquelas que detêm a concessão federal para explorar a prestação de serviços públicos de distribuição de energia elétrica.

Como já mencionado, a implementação da ouvidoria na Celesc é anterior à Resolução Normativa. Tendo decorrido dois anos da vigência da Referida Resolução, a ANEEL, no ano de 2014, encaminhou ofício à Celesc solicitando documentação comprobatória da implementação da ouvidoria. A ouvidoria da Celesc possui autonomia, ela não está subordinada a nenhum departamento, ou seja, é um órgão staff com o propósito de assessorar a presidência, conforme Figura 1.

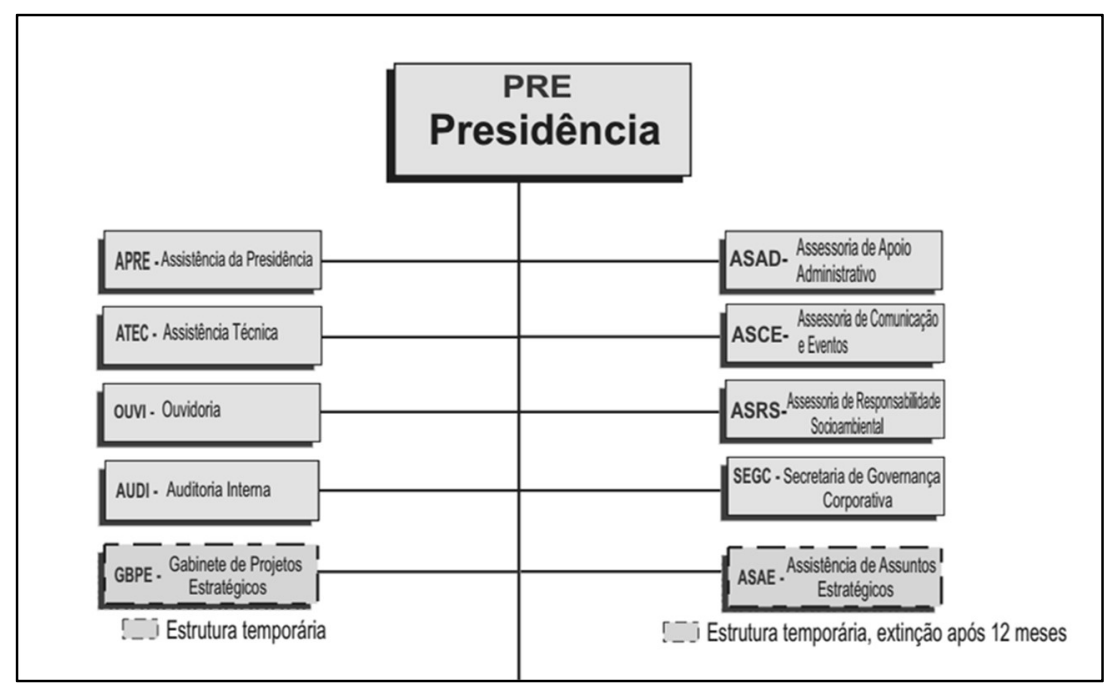

Figura 1: Organograma CELESC. 
Tal fato é observado na fala do ouvidor ao mencionar que: A ouvidoria não está subordinada a nenhum departamento. $\mathrm{O}$ ouvidor é um assistente do presidente. Então, eu não me reporto a nenhum diretor, só ao presidente.

A autonomia é um requisito para a efetividade da ouvidoria pública, isto é, se não existir autonomia o ouvidor e sua equipe podem sofrer influências da organização e dessa forma podem limitar a sua função. Segundo a Cartilha de Implantação de Ouvidorias (2012), "deve ser estabelecido um clima organizacional receptivo, de compromisso institucional em apoio ao ouvidor e com normas gerais que garantam sua autonomia". De acordo com Cardoso, Alcantara e Neto (2011) "para que a ouvidoria pública exerça o seu papel de instância de participação democrática, orientada para atender às demandas do cidadão, é fundamental que tenha autonomia e accountability".

\title{
Perfil do Ouvidor e Perfil da Equipe
}

O ouvidor trabalha há trinta e cinco anos no setor público e atua na ouvidoria da Celesc desde 2003. Seu nível de escolaridade é superior completo, na área de nutrição. O ouvidor não havia desempenhado a função antes de atuar na Celesc, porém ele acredita que, mesmo sendo áreas totalmente distintas, foi possível conciliar a experiência da nutrição com a ouvidoria. Segundo ele, o nutricionista está acostumado a lidar com o público e está disposto a entender o problema do paciente, essas experiências ajudaram na sua atuação como ouvidor. Eu aprendi como nutricionista, o paciente afirma "a comida está uma porcaria", "mas porque está uma porcaria? ", porque ele brigou com a mulher o prato dele está horrível. Eu aprendi e fazia isso na nutrição e trouxe para a Ouvidoria. Você começa a filtrar o que realmente aconteceu.

É possível perceber que a habilidade humana de relacionamento é muito exigida do ouvidor. $O$ fato é citado por ele: A questão humana o ouvidor precisar ter, não só o ouvidor, todas as pessoas da ouvidoria (...) você tem que ter esse, sentimento de que você está tentando, a pessoa que está falando contigo já passou por muita gente e já está muito triste, muito bravo, revoltado e você tem que ter essa compreensão. Não adianta você levantar a voz com ele, um monte de gente já levantou a voz com ele. Lima (2010) esclarece que:

\begin{abstract}
A habilidade humana de relacionar-se com o outro é mais exigida em algumas atividades profissionais que em outras, no entanto uma coisa parece certa: quando se trata da construção do perfil do ouvidor é clara a necessidade de habilidades de relacionamento humano, pois ele será aquele que de fato ouve e percebe o cliente / cidadão. O ouvidor pode possuir uma excelente capacidade técnica e jurídica além de total conhecimento e domínio da organização onde atua, entretanto se a estas qualidades não houver a adição de habilidade de relacionamento humano, é fato que as suas ações podem corroer essas outras capacidades.
\end{abstract}

A equipe é composta por seis membros, sendo que nenhum deles havia desempenhado a função anteriormente. Com exceção de um entrevistado que está há oito anos na ouvidoria, os demais atuam a menos de três anos. Os funcionários são distribuídos em dois turnos para que o atendimento seja disponibilizado das $8 \mathrm{~h}$ às $18 \mathrm{~h}$ em dias úteis, conforme determinação da ANEEL.

Quanto ao nível de escolaridade, cinco possuem nível superior, sendo três incompletos, e um com pós-graduação completa. As áreas de formação são bastante heterogêneas, sendo elas: Administração, 
Biblioteconomia, Gastronomia, Ciências Econômicas, Comunicação Social - Publicidade e Propaganda e Gestão e Metodologia do Ensino.

$\mathrm{Na}$ entrevista com o ouvidor foi mencionado que o único requisito para trabalhar na ouvidoria é estar enquadrado no quadro de lotação da Celesc como assistente administrativo, fora isso não é necessária formação específica, pois a empresa proporciona treinamento para os empregados que irão trabalhar na área. O ouvidor ainda explica que: No máximo seis meses que eles estão na ouvidoria, tem que ter um curso de formação especifica no setor de ouvidoria com formação no setor elétrico, porque eles têm que ter conhecimento da 414 (Resolução).

Nas respostas obtidas no questionário a única entrevistada que não havia recebido treinamento estava há apenas quatro meses na ouvidoria e já tinha treinamento planejado. Dessa forma é possível perceber que todos possuem qualificação para realizar suas atividades.

Um fato relevante durante a coleta de dados é que tanto ouvidor quanto os membros da equipe da ouvidoria não haviam desempenhado a função em outra organização. Isso pode ser ao mesmo tempo positivo e/ou negativo para a Celesc. Como aspecto positivo, os empregados não possuem vícios comportamentais de atendimento e foram capazes de construir a ouvidoria da Celesc conforme a demanda de atendimento do setor de distribuição de energia, adaptando as rotinas de acordo com as necessidades trazidas pelo cidadão. Porém, como aspecto negativo, não tendo o embasamento e experiências adquiridas de outras organizações, não é possível fazer um comparativo entre as atividades realizadas na ouvidoria da Celesc e em outras ouvidorias, reconhecendo as experiências de sucesso.

Quando a equipe foi questionada sobre as características pessoais que os indivíduos necessitam ter para atuar na ouvidoria as respostas foram bastante relacionadas ao equilíbrio emocional e psicológico, envolvendo termos como "paciência", "calma", "bom senso", "tranquilidade", "imparcialidade", "mediação". Além disso, o conhecimento das diversas áreas da organização, incluindo a legislação e as Resoluções Normativas foi apontado como fator primordial.

A resposta do ouvidor para a questão das características pessoais foi bastante ligada com a de sua equipe, ao mencionar que paciência, conhecimento, tem que ter conhecimento de tudo, profundamente eu não sei nada dentro da empresa, mas superficialmente eu conheço todas as áreas. Junqueira (2001) afirma que "é exigido do ouvidor um equilíbrio emocional que lhe dê condições de exercer sua função em harmonia com seus colegas de trabalho e com a compreensão necessária das variáveis que envolvem a sua atuação".

Além das questões apontadas pela equipe, o ouvidor acrescentou alguns pontos. Identificou a humildade como uma característica extremamente importante. Para ele o ouvidor precisa ter certeza da informação que está passando para o consumidor, caso ele não tenha, deve ter a humildade de verificar e depois responder ao cidadão a informação correta. O ouvidor relata que: tem que ter um cuidado muito grande, na informação que vai ser passada. Se eu não souber uma coisa, eu vou me informar e depois te informo, porque eles (consumidores) entendem que o ouvidor é a última instância dentro da empresa para recorrer a alguma coisa. 
Vera Giagrande (2001) utiliza o termo persuasão como uma característica do ombudsman que seriam as "habilidades de organizar, apresentar e transmitir convincentemente suas ideias", afirma ainda que o ouvidor não deve transmitir insegurança ao consumidor.

Ainda relacionada às características pessoais, o ouvidor usou termos como "cautela" e "adaptação", justificando que a ouvidoria não possui uma rotina, que as demandas dos cidadãos são distintas e precisam ser resolvidas da melhor maneira possível pela empresa. Vera Giagrande (2001) define a adaptabilidade do ombudsman como a capacidade de "atuar conforme o momento e a necessidade apresentada. Saber ser duro e inflexível, mas também ser maleável, se for preciso".

O ouvidor relatou que, além de atender ao consumidor, ele tem o papel de coordenar a equipe da ouvidoria, monitorar as manifestações recebidas, quando necessário, interferir no atendimento da equipe, representar a ouvidoria e produzir relatórios gerenciais. Segundo Lima (2010) "ao ouvidor é necessário muito mais que conhecimento técnico para prestar a melhor assistência, é preciso habilidade em tratar aquela pessoa e todo o seu conjunto de emoções, gerando competência gerencial". Oliveira (2005) afirma que "a eficiência da ouvidoria dependerá exclusivamente das condições e competência profissional de quem a dirige", denominada por Lima (2010) como competência ouvidor-gestor.

As ouvidorias necessitam de ouvidores com um novo perfil, não é mais suficiente ser ético e comprometido com o cliente/cidadão apenas, é preciso desenvolver competência gerencial para fazer da ouvidoria uma área estratégica que gere resultados efetivos para a organização e para a sociedade. (LIMA, 2010)

\section{Dimensão Funcional}

Na visão do ouvidor da Celesc a principal função da ouvidoria é ser o segundo nível de atendimento ao consumidor, tentar analisar e resolver uma manifestação que o consumidor fez no primeiro nível de atendimento e não foi atendido ou não ficou satisfeito. Para esclarecer o ouvidor explicou que o primeiro nível de atendimento envolve o Call Center e as lojas de atendimento e o terceiro nível seria de responsabilidade da ANEEL.

$\mathrm{Na}$ resposta obtida é possível perceber que o ouvidor tem conhecimento das normas que fundamentam a ouvidoria da Celesc. Segundo a Resolução Normativa no 470/2011, da ANEEL, compete à ouvidoria receber, registrar, instruir, analisar e dar tratamento adequado às manifestações relativas à prestação do serviço que não forem solucionadas pelos demais canais de atendimento disponibilizados pela distribuidora.

A questão aplicada com a equipe, referente a dimensão funcional, foi aberta e teve como objetivo analisar se as atividades diárias estão vinculadas a função da ouvidoria na organização. Nas seis respostas obtidas a função da ouvidoria é intermediar, mediar, conectar, ser o canal de ligação e ponte entre a organização e o consumidor. No cotidiano, isso é feito desde o recebimento das manifestações e reclamações, passando pelo tratamento, encaminhamento a área técnica responsável até a resposta e solução dos problemas. 
As atividades dos membros da equipe envolvem atendimento de ligações, elaboração de respostas aos consumidores, encaminhamento de e-mails, atendimento ao Programa de Proteção e Defesa do Consumidor - PROCON, abertura e acompanhamento das manifestações, redirecionamento do cidadão ao nível de atendimento correto e respostas as manifestações da ANEEL.

É importante destacar que a ouvidoria da Celesc está vinculada ao PROCON e a ANEEL, ou seja, as manifestações podem surgir também por essas duas organizações. No PROCON, a Celesc possui um número de telefone específico. O ouvidor explicou que muitas vezes o cidadão busca o PROCON sem antes entrar em contato com a Celesc e por meio desse número a manifestação é encaminhada para a Celesc para que a ouvidoria a registre. As manifestações vindas da ANEEL ocorrem quando o consumidor procurou diretamente a agência reguladora, como já explicado, ela é o terceiro nível de atendimento e por isso cabe a ela verificar se o consumidor registrou manifestação anteriormente na Celesc. Além disso, a ANEEL fiscaliza se a Celesc está cumprindo o prazo estipulado para responder o consumidor. Neste ponto é possível verificar que a organização está disposta a fornecer ao cidadão diferentes canais de atendimento, para que assim ele possa ser atendido de acordo com suas necessidades.

Com o objetivo de entender de que forma as atribuições da ouvidoria são alcançadas, ou seja, como são colocadas em prática nas atividades diárias foi elaborado o mapeamento do processo a partir do que foi relatado pelo ouvidor.

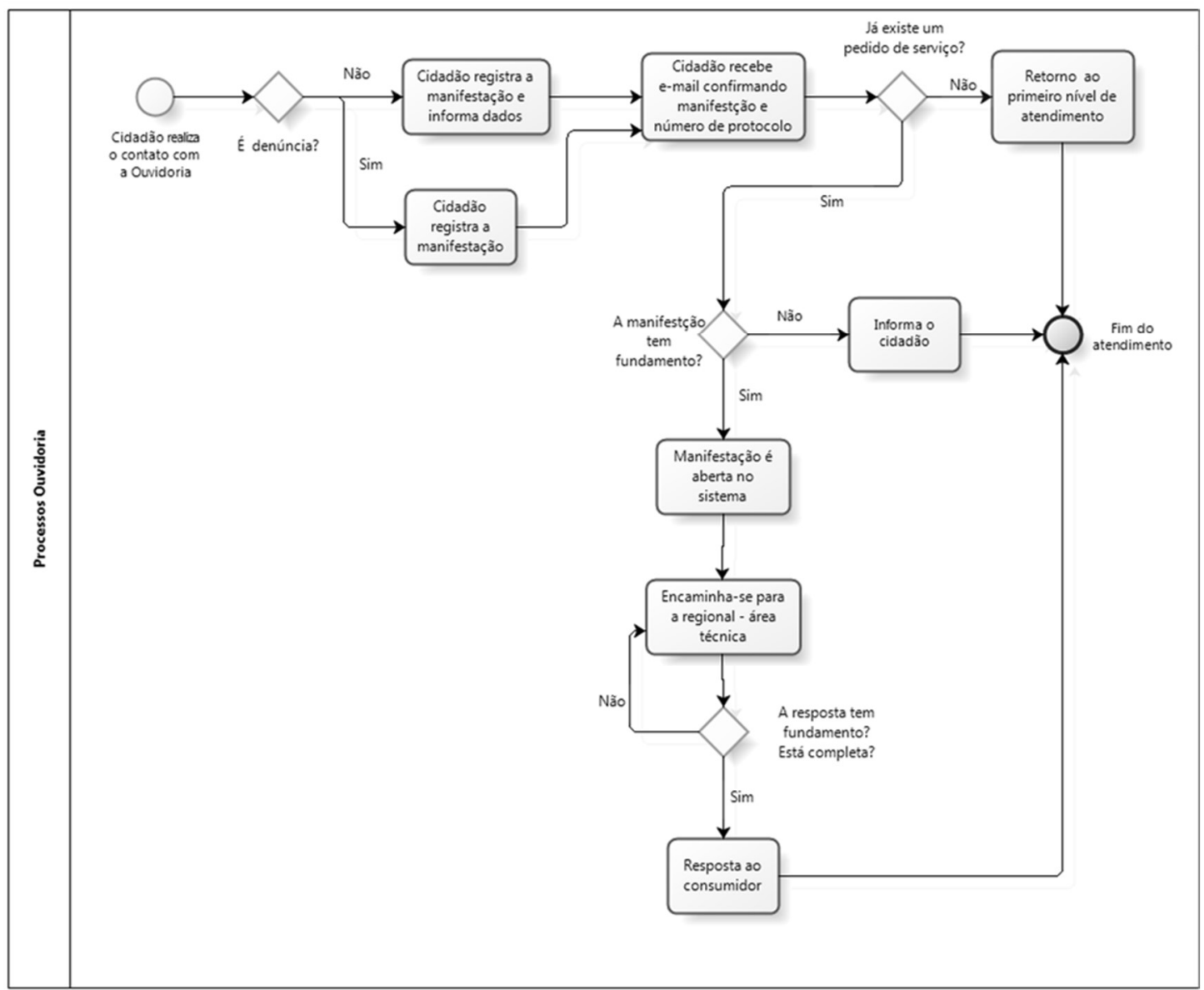

Figura 2: Processo da Ouvidoria. 
O fluxo demonstra quais são as atividades da ouvidoria desde o recebimento da manifestação do consumidor, até a finalização do atendimento. Vale destacar que ao registrar a manifestação o cidadão recebe um número de protocolo através do sistema da ouvidoria, e por meio dele o consumidor pode acompanhar toda a tramitação do processo e no término o cidadão também recebe uma resposta.

De acordo com Serra, Carvalho, Carneiro (2012, p.149) “O acompanhamento das demandas deve ser público, confiável e transparente. O tempo de resolução das questões deve ser previsto em norma e razoável”. Conforme Resolução Normativa nํ470/2011, Art. 4ㅇ §2:

A Ouvidoria deve disponibilizar meios para o acompanhamento do atendimento pelo manifestante, mediante solicitação telefônica ou por escrito, garantindo o acesso a todos os dados registrados sob o número de protocolo informado, preservado o sigilo das informações relativas a unidades consumidoras titularizadas por terceiros.

\section{Dimensão Gerencial}

Referente à dimensão gerencial foram avaliados os seguintes aspectos: a suficiência do número de membros da equipe, a satisfação do consumidor, o sistema de informação utilizado, o conhecimento do regulamento da ouvidoria, o papel na organização, o aprimoramento dos serviços da organização e a avaliação realizada da ouvidoria.

Mesmo que de forma parcial ou total, todos os membros da equipe julgaram que a quantidade de funcionários é suficiente para o desempenho das funções. O ouvidor afirmou que cinco funcionários conseguiriam suprir as funções, porém devido a férias, faltas e licenças, seis são o ideal.

Com relação a satisfação do consumidor com o serviço prestado, todos apontaram para a subjetividade desse aspecto, uma vez que os cidadãos relacionam a eficiência do serviço da ouvidoria com a sua necessidade, isto é, de forma sintetizada, se o problema do cidadão foi resolvido ele considera o serviço eficiente e mostra-se satisfeito. Apesar desse grau de subjetividade, de forma geral foi considerado que a ouvidoria é capaz de satisfazer o consumidor.

Acerca da adequação do sistema de informação utilizado para gerenciar as manifestações as respostas foram diversificadas, um membro não considera adequado, três parcialmente e dois totalmente adequado.

O ouvidor afirmou que o sistema é bastante completo e útil no cotidiano da ouvidoria, por meio dele é possível o acompanhamento da manifestação desde o início até o término. Acrescentou que: Nós tínhamos um sistema primeiro, era desenvolvido por aqui, porém se tornou obsoleto, depois nós compramos um sistema fora que gerencia toda a demanda, desde a entrada, o encaminhamento de todas as manifestações, começo, meio e fim.

O conhecimento do regulamento foi positivo, sendo que dois membros da equipe afirmam ter conhecimento total e quatro parciais. O ouvidor apontou como dificuldade para atuação na ouvidoria a abrangência de informações, afirmando que o setor elétrico é extremamente complexo e que as normas e regulação da ANEEL e da Celesc são específicas. Como ele não atuou em outra ouvidoria, ele afirmou não saber se essa dificuldade é uma particularidade da ouvidoria do setor elétrico. 
Todos da equipe asseguraram ter totalmente clara a percepção do papel da ouvidoria na instituição. Segundo o ouvidor a atuação da ouvidoria já se solidificou na Celesc, porém em algumas áreas, alguns casos bem pontuais, ainda existe resistência interna. O ouvidor argumenta que: eu diria assim que $95 \%$ eu não tenho problema, os problemas que tenho seriam quase que pessoal.

Baesso (2013) expõe a importância de a organização conhecer a função da ouvidoria:

A compreensão da cultura organizacional e do comportamento dos indivíduos e dos grupos configura-se como elemento fundamental para que a ouvidoria possa atuar na promoção das mudanças nos processos. Concomitantemente, os resultados sinalizam a importância de se difundir o papel e a forma de atuação da ouvidoria dentro das organizações, estabelecendo relações internas de parceria.

A Cartilha de Implantação de Ouvidorias (2012), enfatiza que "Se os canais internos da organização estiverem bloqueados e as relações complicadas, o ouvidor pouco poderá contribuir. Acrescenta também que "para promover as mudanças necessárias às soluções dos problemas identificados é imprescindível a aceitação do ouvidor pelos administradores e funcionários".

De forma parcial ou total, a equipe garantiu que devido ao recebimento de alguma manifestação na ouvidoria os serviços da organização foram aperfeiçoados. "O cidadão, usuário direto dos serviços, além da oportunidade de efetivamente exercitar a sua cidadania, passa a vislumbrar a melhoria da qualidade dos serviços e a solução dos problemas emergentes. " (OLIVEIRA, 2001).

O ouvidor afirma que uma das funções da ouvidoria é justamente essa, a partir de alguma reclamação do cidadão verificar se ela é pontual ou se a empresa está realizando algum procedimento de forma incorreta ou, mesmo que esteja sendo concretizado de forma correta, se existe a possibilidade de aperfeiçoar os processos. Ele esclarece que: mudar procedimentos da empresa é uma das demandas que a gente recebe (...) Esse é um dos objetivos principais da ouvidoria, que eu considero, é mudar os procedimentos que, por ventura, estejam errados ou mal interpretados.

Lima (2010) descreve que as manifestações recebidas em uma ouvidoria são como "diamantes brutos que precisam ser lapidados e ao final, transformados em bem mais valioso. São delas que surgem as melhorias de processos e das gestões através de críticas e sugestões, assim como os processos de denúncias". O ouvidor explicou que a ouvidoria não tem o papel de determinar mudanças, ela pode sugerir melhorias. De acordo com a Cartilha de Implantação de Ouvidorias (2012),

Os poderes do ouvidor, na Administração Pública, são de inspeção e de persuasão. Ele não tem poder coercitivo, mas se impõe pela legitimidade de seus argumentos baseados, sobretudo na análise das manifestações dos cidadãos e pela agilidade no acionamento correto dos órgãos competentes. Por não possuir poderes coercitivos, o ouvidor necessita do respaldo interno da organização, sob pena de ter sua aceitação, credibilidade e capacidade de resposta prejudicada.

O aspecto avaliatório foi explorado somente com o ouvidor da Celesc. Ele afirmou que a ouvidoria é basicamente avaliada externamente pelo consumidor por meio do sistema. E que internamente, o ouvidor é avaliado pelo presidente e a equipe é avaliada pelo próprio ouvidor. Além disso, a ANEEL acompanha os resultados de todas as ouvidorias do setor. 
É importante salientar que outra atividade da dimensão gerencial está relacionada ao desenvolvimento de relatórios baseados nas informações coletadas pela ouvidoria, porém devido a sua vinculação com a dimensão cidadã esse aspecto será abordado posteriormente.

\section{Dimensão Cidadã}

Na dimensão cidadã, foram analisadas as principais demandas e a eficiência da ouvidoria em atendêlas, as formas de contato disponíveis ao cidadão, a facilidade de acesso ao site, o estímulo dado à população para procurar a ouvidoria, a importância atribuída a ela, a contribuição da ouvidoria para promover ou facilitar o exercício da cidadania e o desenvolvimento da accountability por meio de relatórios.

As principais demandas da ouvidoria estão relacionadas à interrupção e oscilação de energia e ressarcimento de danos. O ressarcimento ocorre quando equipamentos elétricos de unidades consumidoras são danificados por deficiências ou anormalidades no sistema elétrico da Celesc, ou por obras e atos necessários para a manutenção, operação e ampliação da empresa. Referente a esse aspecto, a equipe ficou dividida, sendo que três acreditam que a ouvidoria atende totalmente as demandas e três afirmaram que atende parcialmente. O ouvidor também acredita que as demandas são atendidas, porém salienta que: Na minha opinião as demandas são atendidas sim. Poderia ser feito mais? Sim! Eu acho que a gente consegue fazer o atendimento ao consumidor. Eu espero que sim.

A ouvidoria da Celesc atende o estado de Santa Catarina inteiro por meio da sede administrativa localizada em Florianópolis. O ouvidor entende que uma estrutura descentralizada poderia proporcionar o melhor atendimento das demandas. Na empresa já existe, de certa forma uma descentralização, já que cada regional possui um agente de ouvidoria. Como a Celesc possui no total 16 regionais, o ouvidor conta com 16 agentes de ouvidoria. Esses agentes estão próximos ao operacional da Celesc e então eles auxiliam o ouvidor: Ele (agente) é o meu contato com as pessoas do operacional dentro das regionais, isso ajudou bastante. Nesse ponto a ouvidoria conseguiu entrar em todas as 16 regionais.

As formas de contato que o cidadão tem com a ouvidoria ocorrem por meio de telefone (0800), email, site, fax, presencial e caixa de sugestão na organização. Segundo o ouvidor a maioria das manifestações ocorrem por telefone, seguida por e-mail e site, e em menor número, por fax e presencial. A Celesc conta com a Unidade de Resposta Audível - URA que é utilizada para o fornecimento de serviços através de telefone, permitindo ao consumidor interagir com aplicações diversas direcionando ao nível de atendimento adequado para sua manifestação.

Relacionado ao site, apenas um integrante da equipe afirmou que o mesmo não é de fácil acesso. O ouvidor explicou que a ouvidoria se encontra na área do "Fale conosco" por um acordo entre a área comercial e a área de Tecnologia da Informação da Celesc, por uma questão de padronização do site da empresa. Justifica que ficou, mais ou menos definido isso porque eles não querem um destaque ou uma alta atenção, eles querem que todos os consumidores tenham um atendimento linear. Serra, Carvalho, Carneiro (2012) afirma que: 
Os canais de recepção das manifestações da ouvidoria devem ser atuais e variados, por meio eletrônico, de telecomunicações e pessoalmente, disponibilizados de maneira fácil para os interessados. O acompanhamento das demandas deve ser público, confiável e transparente.

A decisão afirmativa foi unânime quando questionado o estímulo repassado ao cidadão para buscar a ouvidoria, os membros da equipe citaram que a divulgação da existência da ouvidoria ocorre de diversas maneiras: através da fatura de energia elétrica, no momento em que o cidadão recorre as lojas de atendimentos existem cartazes, no site da Celesc.

O ouvidor relatou as mesmas formas de estímulo que a equipe e informou que já existiu uma campanha informativa sobre a ouvidoria da Celesc, só que o resultado não foi o desejado. Na época da campanha o número de manifestações aumentou drasticamente e a maioria das manifestações eram de primeiro atendimento. Devido a essa experiência, a organização não realizou mais nenhuma campanha de divulgação.

Com relação à importância atribuída à ouvidoria, foi afirmado por todos os entrevistados que ela é muito importante na atuação das manifestações dos consumidores. Antunes, Freitas e Ribeiro (2007, p.5) afirmam que a ouvidoria é um instrumento de grande importância para "participação cidadã e de possibilidade do controle social, de forma direta, na Administração Pública, na medida em que possibilita à sociedade expressar as suas necessidades".

As respostas referentes ao apoio promovido ou facilitado da ouvidoria para o exercício da cidadania, também foram positivas, com apenas um membro da equipe afirmando que a ouvidoria atenderia parcialmente esse quesito.

O ouvidor respondeu que o exercício da cidadania ocorre pelo atendimento diferenciado prestado pela ouvidoria. Ela é capaz de realizar o atendimento personalizado e individualizado para o consumidor que já passou pela loja de atendimento e pelo Call Center e não teve seu problema solucionado. A importância da aproximação é mencionada pelo ouvidor: Você está dando uma oportunidade da pessoa se manifestar, ela não está falando com uma máquina (...) dá uma liberdade para pessoa falar, a pessoa se sente mais cidadã.

Segundo o ouvidor quando o cidadão entra em contato, o empregado que está atendendo consegue acompanhar pelo sistema todo o histórico da unidade consumidora e dessa forma o consumidor percebe que não é apenas mais um reclamante, mas que a Celesc está preocupada em atendê-lo como cidadão. A partir do momento que o ouvidor e sua equipe estão dispostos a entender que o consumidor tem problemas pessoais, muitas vezes relacionados à saúde, ele desenvolve o exercício da cidadania. De acordo com a Cartilha de Implantação de Ouvidorias (2012, p.8), a ouvidoria

Deve atuar no processo de interlocução entre o cidadão e a Administração Pública, de modo que as manifestações decorrentes do exercício da cidadania provoquem contínua melhoria dos serviços públicos prestados. A existência de uma unidade de ouvidoria na estrutura de um órgão público pode estreitar a relação entre a sociedade e o Estado, permitindo que o cidadão participe da gestão pública e realize um controle social sobre as políticas, os serviços e, indiretamente, os servidores públicos. 
A elaboração de relatórios da ouvidoria da Celesc foi contemplada por todos. O ouvidor confirmou que são produzidos relatórios mensais e que os mesmos ficam disponíveis no sistema da Celesc para consulta interna. Anteriormente os relatórios eram públicos, porém foram retirados do site pelo fato de a Celesc ser uma empresa com ações na bolsa de valores e por questões estratégicas os relatórios públicos passaram a ter outro padrão de informação.

O desenvolvimento desses relatórios contribui para a promoção da transparência das manifestações recebidas e das respostas dadas a elas. "Considerada um instrumento de controle social e mantendo uma forte relação com a accountability, a ouvidoria pública passa a ser fundamental na conjuntura de uma gestão transparente" (TORTOLANO; CRUZ; ALMEIDA, 2011).

O ouvidor foi questionado sobre o conhecimento do termo "accountability" e ele afirmou desconhecer o termo. É possível perceber nesse aspecto um distanciamento entre termos acadêmicos e a realidade, ou seja, alguns termos utilizados nas universidades podem não pertencer ao cotidiano das organizações públicas. Serra, Carvalho, Carneiro (2012, p.149) estabelece a conexão entre ouvidoria e accountability, revelada no desenho institucional,

Acerca das variações decorrentes do desenho institucional, no tocante às ouvidorias, é plausível considerar que o seu desenho irá caracterizá-la, conferindo-lhe peculiaridades que a aproximarão, ou não, do real exercício da participação democrática. Precisar os limites da atuação do ouvidor e da sua equipe e estabelecer os filtros, políticos ou técnicos, aos quais se submeterão as manifestações recebidas pela ouvidoria; as formas de acesso para comunicação do cidadão; o grau de facilidade ou dificuldade para o acesso do cidadão que pretenda efetuar denúncia; o caráter de autonomia ou independência que as ouvidorias deterão em relação ao comando dos órgãos ou entidades aos quais pertençam. Tudo isso reflete no desenho institucional da ouvidoria e, por consequência, a caracteriza. O resultado das escolhas feitas evidenciará um modelo de ouvidoria que propiciará condições para o fortalecimento ou para a fragilização do processo de accountability democrática a ser por ela desempenhado.

Sendo assim, é possível verificar que, apesar de desconhecer o significado do termo accountability, ela é desenvolvida na ouvidoria da Celesc conforme tudo o que foi relatado.

\section{DISCUSSÃO}

Por meio dos dados levantados foi confeccionado um quadro síntese abordando os principais tópicos analisados:

Tabela 3: Quadro Síntese: Ouvidoria da Celesc.

\begin{tabular}{l}
\hline Aspectos Estruturais \\
\hline A ouvidoria foi instituída no ano 1996; \\
Surgiu antes da Regulamentação da ANEEL e da Ouvidoria Geral do Estado de Santa Catarina. \\
É um órgão staff, com o objetivo de auxiliar a presidência; \\
Possui autonomia; \\
\hline Perfil do Ouvidor e da Equipe \\
\hline Ouvidor possui experiência no setor público; \\
A equipe é composta por seis membros; \\
Áreas de formação são heterogêneas; \\
Nenhum membro havia desempenhado função na ouvidoria anteriormente; \\
As características pessoais apontadas como imprescindíveis estão relacionadas ao equilíbrio emocional e o \\
conhecimento da organização como um todo.
\end{tabular}




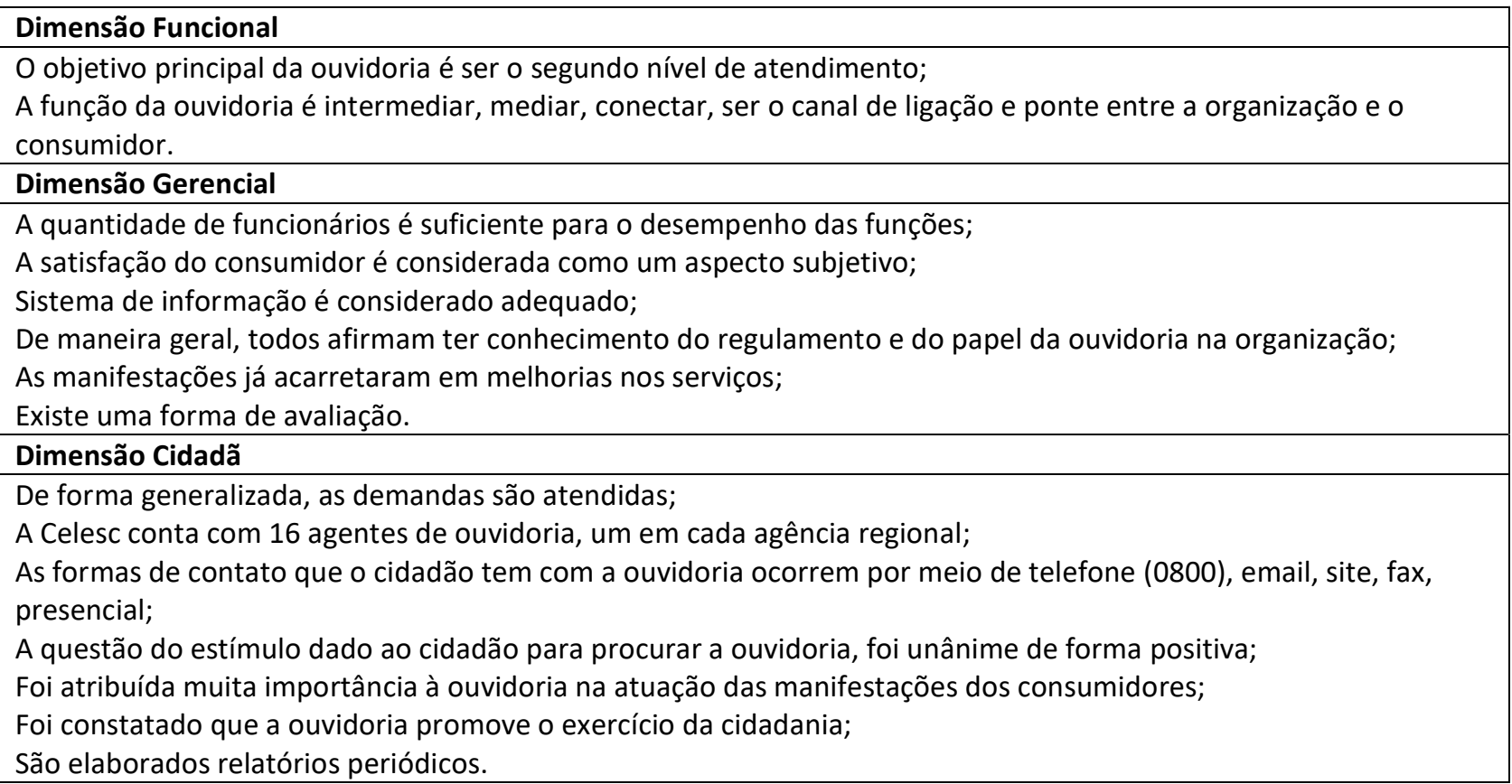

\section{CONCLUSÃO}

A pesquisa proporcionou a ampliação sobre o entendimento do tema ouvidoria púbica. A partir do estudo de caso, foi possível perceber a uniformidade entre as teorias apresentadas sobre o assunto e a realidade vivenciada pela ouvidoria da Celesc.

Fazendo um paralelo com as perspectivas de atuação da Cartilha de Implantação de Ouvidoria (CGUOGU, 2012), foi possível concluir que a ouvidoria da Celesc facilita ao usuário o acesso à informação, uma vez que dispõe de diversos meios de comunicação. Além disso, consegue sensibilizar dirigentes, contribuir para o aprimoramento de serviços prestados e aperfeiçoamento das normas e procedimentos, pelo fato de já ter apresentado situações de mudanças e melhorias nos serviços da organização motivados por manifestações recebidas. A ouvidoria da Celesc busca, também, manter bom relacionamento do usuário com a instituição, sendo imparcial nas suas ações. Ainda foi possível perceber que a ouvidoria proporciona transparência das suas ações, uma vez que o cidadão pode acompanhar a tramitação do procedimento e sua conclusão. Outro ponto conclusivo foi o incentivo a participação e a valorização do capital humano, uma vez que todos os membros da equipe e o ouvidor apontaram que o cidadão precisa ser ouvido na administração pública e o papel da ouvidoria seria justamente esse. E por fim, ficou evidenciado que a ouvidoria contribui para a melhoria da imagem da instituição pelo fato de proporcionar ao cidadão usuário do serviço público uma relação baseada na confiança.

É importante destacar que os resultados encontrados no estudo, não significam que a realidade das demais ouvidorias públicas seja a mesma. Com os resultados apresentados, tornam-se pertinentes alguns questionamentos relacionados à ouvidoria pública. Quais seriam os fatores determinantes para que as funcionalidades teoricamente expostas sejam colocadas em prática na rotina da administração pública? Com base no estudo, possíveis fatores determinantes seriam a legitimidade da ouvidoria dentro da própria 
organização, o tempo de funcionamento e a estrutura hierárquica adequada que garanta autonomia para a ouvidoria.

Outro questionamento seria, de que forma os aspectos legais de uma ouvidoria garantem que a ouvidoria cumpra a função determinada a ela? Devido ao fato de que as organização da administração pública serem pautadas por lei, sejam elas pertencentes a administração pública direta ou indireta, os requisitos legais sobre ouvidoria irão basear as suas finalidades, porém somente os dispositivos legais não conseguem garantir a efetividade das atribuições de uma ouvidoria pública.

Por fim, a última indagação é a população tem conhecimento e utiliza a ouvidoria como instrumento de comunicação com o poder público? É importante ressaltar que o efetivo sucesso de uma ouvidoria pública não depende somente de sua estrutura, funcionamento, requisitos legais e ações. Com o propósito de que sua finalidade seja de fato atingida, é necessário que os cidadãos almejem serviços públicos de qualidade e sejam capazes de exigi-los da administração. Para que isso acontece, é preciso que os cidadãos usuários do serviço público tenham conhecimento e utilizem de fato a ouvidoria como instrumento de comunicação com a administração pública.

Como mencionado no estudo, o tema possui pouca produção acadêmica e a visão do cidadão é pouco abordada. A ouvidoria pode ser considerada instrumento da nova gestão pública capaz de promover a participação cidadã e o aprimoramento dos serviços públicos. Além disso, em conjunto com a Constituição Federal de 1988 a ouvidoria pública tem importante papel na ampliação do exercício da cidadania, e, consequentemente no fortalecimento da democracia. Sendo assim, cabe a sugestão de novas pesquisas relacionadas ao tema, tanto nas perspectivas organizacionais quanto na percepção do cidadão e usuário do serviço público.

\section{REFERÊNCIAS}

ANEEL. Agência Nacional de Energia Elétrica. Resolução Normativa № $\mathbf{4 7 0}$. Estabelece as disposições relativas às Ouvidorias das concessionárias de serviço público de distribuição de energia elétrica e dá outras providências. Brasília: ANEEL, 2011.

AMARAL FILHO, M. J. T.. O ombudsman e o controle da administração. São Paulo: EDUSP, 1993.

ANTUNES, C. K. S.; FREITAS, N. M. B.; RIBEIRO, J. F. F.. Ouvidoria: inter-relação entre controle social e controle interno. Espaço Acadêmico da Ouvidoria do IPEA, 2007.

BAESSO, R. S.. Ouvidorias: Mecanismos Singulares de Governança. Encontro da ANPAD, 37. Anais. Rio de Janeiro, 2013.

BORDENAVE, J. E. D.. O que é participação?. 7 ed. São Paulo: Brasiliense, 1992.

BRASIL. Lei no 9427, de 26 de dezembro de 1996. Institui A Agência Nacional de Energia Elétrica - Aneel, Disciplina O Regime das Concessões de Serviços Públicos de Energia Elétrica e dá Outras Providências. Brasília: DOU, 27 dez 1996
BRASIL. Constituição (1996). Lei no 7783, de 28 de junho de 1989. Dispõe sobre o exercício do direito de greve, define as atividades essenciais, regula o atendimento das necessidades inadiáveis da comunidade, e dá outras providências. Brasília: DOU, 26 jun 1989.

BRASIL. Controladoria Geral da União. Ouvidoria Geral da União. Instrução Normativa $\mathbf{n}^{\circ} \mathbf{1}$ de 05 de novembro de 2014. Brasília: DOU, 2014.

BRAZ, A. C. A.. Corrupção: combate pelo ombudsman paramentar: ouvidoria do povo. Porto Alegre: Serpio Antonio Fabris, 1992

CARDOSO, A. S. R.. Ouvidoria Pública Como Instrumento de Mudança. Texto para Discussão n.1480. Brasília: IPEA, 2010.

CRESWELL, J. W.. Projeto de pesquisa: métodos qualitativo, quantitativo e misto. Porto Alegre: Artmed, 2007.

CUNHA, S. S.. O controle social e seus instrumentos. In: MILANI, C.. Capital Social, Participação Política e Desenvolvimento Local na Bahia: atores da sociedade civil e políticas de desenvolvimento local na Bahia. Salvador: UFBA, 2003. 
GIL, A. C.. Métodos e Técnicas de Pesquisa Social. 6 ed. São Paulo: Atlas, 2008.

LIMA, C. S.. Ouvidor-Gestor: a necessidade da ouvidoria moderna. Revista Gestão Pública: Práticas e Desafios, Recife, p.205-224, 2010.

LYRA, R. P. Autônomas $x$ obedientes: a ouvidoria pública em debate. João Pessoa: UFPB, 2004

OUVIDORIA-GERAL DA UNIÃO. CGU. Orientações para Implantação de Unidade de Ouvidoria. 5 ed. Brasília: ASCOM/CGU, 2009a.
OUVIDORIA-GERAL DA UNIÃO. CGU. Manual Para Ouvidores Federais. Brasília, 2015

RAMOS, P.; RAMOS, M. M.; BUSNELLO, S. J.. Manual prático de metodologia da pesquisa: artigo, resenha, projeto, TCC, monografia, dissertação e tese. Blumenau: Acadêmica, 2005.

SANTOS, M. A. C.. Controladoria, Ouvidoria e Procuradoria no exercício do controle interno na Administração Pública Estadual Pernambucana. Revista do Centro de Estudos Jurídicos, Recife, v.4, n.4, p.74-105, 2011.

SANTOS, A. R.; COSTA, J. I. P. C.; STAHELIN, F. C.; LUCA, C. A. A produção acadêmica sobre Ouvidoria Pública: um estudo em eventos e periódicos no período de 2002 a 2013. In: ENCONTRO DA ANPAD, 39. Anais. Belo Horizonte, 2015. 